\title{
HYDROCRACKING OF FISCHER-TROPSCH PRODUCTS
}

\author{
U. M. Teles and \\ F. A. N. Fernandes \\ ABSTRACT \\ The hydrocracking behavior the product of a Fischer-Tropsch synthesis \\ consisting of a C4-C30 mixture of paraffins and olefins on a \\ platinum/amorphous silica-alumina catalyst has been analyzed and \\ optimized. The influence of temperature on the selectiveness of the \\ hydrocracking has been investigated. Time and temperature optimization \\ was performed in order to obtain the best operating conditions for the \\ enhancement of gasoline and diesel cuts. \\ Departamento de Engenharia Química \\ Campus do Pici, Bloco 709 \\ 60455-760 Forzaleza, CE, Brasil \\ Keywords: hydrocracking, Fischer-Tropsch, modeling \\ fabiano@efftech.eng.br
}

\section{NOMENCLATURE}

$\mathrm{k}_{10} \quad$ rate constant for a hydrocarbon with 10 carbons

$\mathrm{k}_{\mathrm{n}} \quad$ rate constant for a hydrocarbon with $\mathrm{n}$ carbons

$\mathrm{n}$ number of carbons in the hydrocarbon molecule

RR relative reactivity for cracking

$\mathrm{T}$ temperature [K]

\section{Greek symbols}

$\rho_{\mathrm{b}} \quad$ catalyst density $\left[\mathrm{g} / \mathrm{m}^{3}\right]$

\section{INTRODUCTION}

Environmental concerns and new liquid fuels regulations to take place in 2008 in Europe and in the US has lead to the production of less pollutant fuels with lower emissions of SOx and NOx. In this context, "green" gasoline and diesel are of special interest. These clean fuels can be easily produced by Fischer-Tropsch synthesis using natural gas or biomass as feedstock. These FTS products are mainly composed of long-chain normal paraffins, containing no sulfur or nitrogen and only trace amount of aromatics and heavy metals. They are an environmentally clean source for transportation fuels and lube-base oils either alone or blended with petroleum-based products.

The Fischer-Tropsch Synthesis (FTS) converts a mixture of $\mathrm{CO}$ and $\mathrm{H}_{2}$ (syngas) to a range of hydrocarbons and is an alternative to petroleum sources for the production of liquid fuels. In commercial practice, the FTS process is suited for the production of high-quality gasoline and diesel fuels, but during the synthesis hydrocarbons heavier than the diesel cut, i.e. waxes, are produced. These waxes can be cracked selectively yielding hydrocarbons in the diesel or gasoline cut.
In this work a mathematical model of a batch reactor used for hydrocarbon hydrocracking was developed and the process was studied from a modeling point of view based on the kinetics of an bifunctional catalyst. Optimizations of gasoline and diesel production were done in order to search for the best operating conditions for their production.

\section{HYDROCRACKING}

The production of paraffins of a specified carbon-number range is not possible by direct FT synthesis, but may be achieved by directing the synthesis towards heavy paraffins, which are subsequently cracked selectively. The cracking process should predominantly fragment the hydrocarbons to a desired range of chain length and the components already in the desired range should not undergo further cracking.

The hydrocracking can be done over a bifunctional (acid/metal) catalyst capable to have its reactivity increased with increasing carbon number of the paraffin. Hydrocracking catalysts are bifunctional catalysts characterized by the presence of acidic sites, which provide the cracking function, and of metal sites with hydrogenation-dehydrogenation function. Typical acidic supports are amorphous oxides or mixtures of oxides, zeolites and silicoaluminaphosphates. Pt, Pd or bimetallic systems (i.e. Ni/Mo, $\mathrm{Ni} / \mathrm{W}, \mathrm{Co} / \mathrm{Mo}$, in the sulfided form) are the most commonly used metals. Conditions favorable for this reaction is at 3.0 to $5.0 \mathrm{MPa}$ total pressure and at temperatures between 550 and $600^{\circ} \mathrm{C}$ (Sie et al., 1991; Pelegrini et al., 2004).

In recent years the hydrocracking of heavy hydrocarbons have been studied by many researchers, especially regarding the hydrocracking of FTS products (Sie et al., 1991; Schweitzer et al., 1999; Calemma et al., 2000; Li et al., 2003; Walendziewski et al., 2003; Zhou et al., 2003), but most researches has been based on the cracking of a specific 
hydrocarbon and not a mixture of hydrocarbons as the FTS product.

The hydrocracking of paraffins and olefins has been studied by Sie et al. (1991) over a bifunctional (acid/metal) catalyst, and it was observed that the reactivity increases dramatically with increasing carbon number of the hydrocarbon chain (Figure 1).

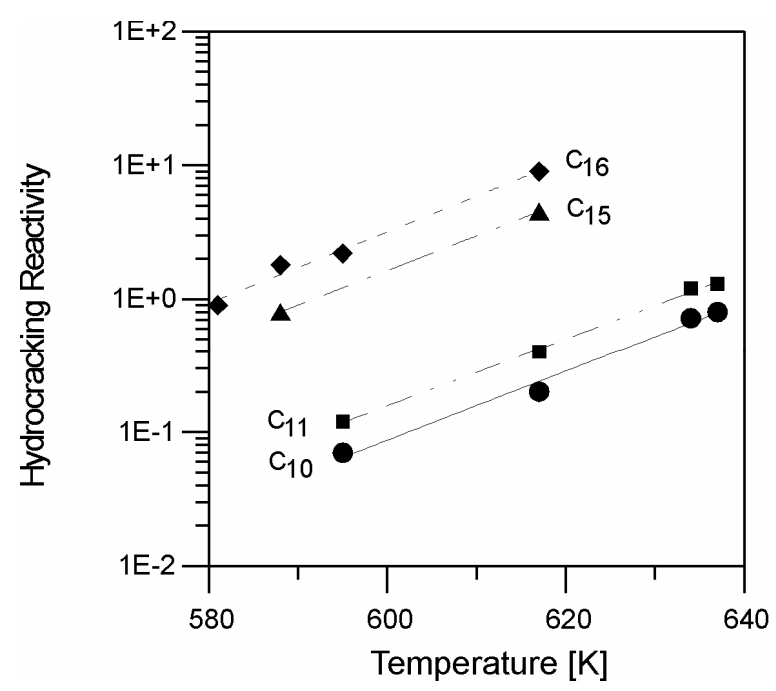

Figure 1. Hydrocracking of paraffins of different chain length over a dual-functional catalyst.

According to Sie et al. (1991) observations, there is a high scission reactivity of more internally located $\mathrm{C}-\mathrm{C}$ bonds, and that terminal or near-terminal C-C bonds show relatively little tendency to break. This preference for breakage of more centrally situated C-C- bonds is a factor, which contributes to the strong dependence of the reactivity of hydrocarbon molecules on chain length.

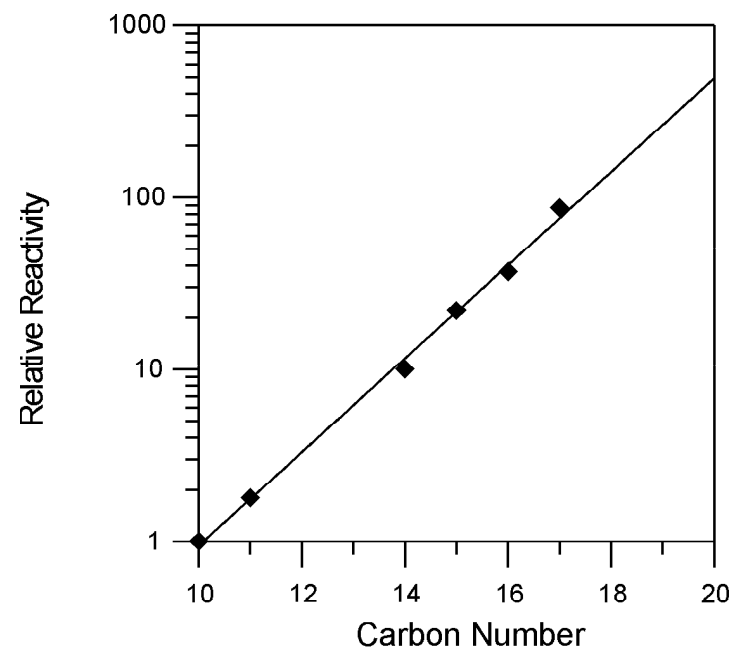

Figure 2. Relative reactivity for cracking of hydrocarbons as function of carbon number.
Figure 2 shows the relative reactivity of hydrocarbons over a dual-functional catalyst, which presents an exponential behavior as function of the number of carbons in the hydrocarbon chain, which can be fit by the equation:

$$
\mathrm{RR}=0.00182 \cdot \exp (0.626 \cdot \mathrm{n})
$$

The kinetic rate constant for the hydrocracking and hydroisomerization for a hydrocarbon with 10 carbons is given by equation 2 and the reaction rates for higher hydrocarbons are obtained by multiplying equations 1 and 2, resulting in equation 3 .

$$
\begin{gathered}
\mathrm{k}_{10}=1.336 \times 10^{17} \cdot \exp \left(\frac{-25173}{\mathrm{~T}}\right) \\
\mathrm{k}_{\mathrm{n}}=2.432 \times 10^{14} \cdot \exp \left(0.626 \cdot \mathrm{n}-\frac{25173}{\mathrm{~T}}\right)
\end{gathered}
$$

\section{MATHEMATICAL MODELING}

The assumptions made for the mathematical models of the batch reactor were: isothermal conditions, negligible mass and heat transfer resistances between the catalyst and the liquid.

The feedstock of the hydrocracker consists mainly of paraffins and olefins. It is considered that the olefin fraction of the feedstock is converted into n-paraffins instantaneously after entering the reactor, since they show a much higher reactivity than nparaffins and readily reacts with the hydrogen feed, according to the reaction (Pelegrini et al., 2004):

$$
\mathrm{O}_{\mathrm{n}}+\mathrm{H}_{2} \rightarrow \mathrm{P}_{\mathrm{n}}
$$

The cracking of n-paraffins occurs according to the following reaction (Sie et al., 1991):

$$
\mathrm{P}_{\mathrm{n}}+\mathrm{H}_{2} \rightarrow \mathrm{P}_{\mathrm{s}}+\mathrm{P}_{\mathrm{r}}
$$

where $n=r+s$

It is generally assumed that cracking generates two hydrocarbons with the same number of carbon atoms (Froment, 1987; Sie et al., 1991; Pelegrini et al., 2004) and as such, it is considered that when $n$ is an even number, $\mathrm{s}=\mathrm{r}=\mathrm{n} / 2$ and when $\mathrm{n}$ is an odd number, $\mathrm{s}=\mathrm{r}+1=(\mathrm{n} / 2+0.5)$.

The mass balance for the reacting species are given by equations:

$$
\frac{\mathrm{dC}(\mathrm{i})}{\mathrm{dt}}=\rho_{\text {cat }} \cdot\left[\begin{array}{l}
\mathrm{k}(2 \cdot \mathrm{i}-1) \cdot \mathrm{P}(2 \cdot \mathrm{i}-1) \\
+2 \cdot \mathrm{k}(2 \cdot \mathrm{i}) \cdot \mathrm{P}(2 \cdot \mathrm{i}) \\
+\mathrm{k}(2 \cdot \mathrm{i}+1) \cdot \mathrm{P}(2 \cdot \mathrm{i}+1) \\
-\mathrm{k}(\mathrm{i}) \cdot \mathrm{P}(\mathrm{i})
\end{array}\right] \cdot \mathrm{H}_{2} \cdot \mathrm{V}_{\mathrm{R}}
$$


Due to the assumption of isothermal conditions in the reactor, which can be considered based on academic reports (Pelegrini et al., 2004), only the mass balances for each hydrocarbon species were considered in this work. As such, all heat produced by the reaction is removed by the cooling jacket of the reactor.

To solve the mathematical model, the equations were numerically integrated using a $5^{\text {th }}$ order RungeKutta method. The operating conditions used in the simulations are presented in Table 1.

Table 1. Operating conditions and reactor parameters.

\begin{tabular}{lc}
\hline Temperature $[\mathrm{K}]$ & $550-650$ \\
Total Pressure $[\mathrm{atm}]$ & 50.0 \\
$\mathrm{H}_{2}$ to paraffin ratio & 0.10 \\
Catalyst density $\left[\mathrm{kg} / \mathrm{m}^{3}\right]$ & 1987 \\
\hline
\end{tabular}

As initial conditions for the numerical integration, all olefin feedstock was converted into paraffins due to the instantaneous reaction of olefins with hydrogen.

$$
\begin{aligned}
& \mathrm{P}_{\mathrm{n}}=\mathrm{P}_{\mathrm{n}}{ }^{\mathrm{F}}+\mathrm{O}_{\mathrm{n}}^{\mathrm{F}} \\
& \mathrm{H}_{2}=\mathrm{H}_{2}{ }^{\mathrm{F}}-\Sigma \mathrm{O}_{\mathrm{i}}^{\mathrm{F}} \quad \mathrm{i}=2 \text { to } 30
\end{aligned}
$$

where the superscript $\mathrm{F}$ represents the concentrations of the species before entering the reactor.

The model was validated with the data provided by Sie et al. (1991).

\section{RESULTS AND DISCUSSION}

In this work, several simulations were performed to understand the effect of temperature and processing time on the product distribution of the hydrocarbon mixture, especially in the range of transportation fuels. The simulation study assumes that the rate laws for the hydrocracking reaction are valid for the entire range of the varied process parameters as observed experimentally by Sie et al. (1991).

The feedstock used in the simulations consisted of a typical FTS product produced in a slurry reactor with the use of an iron-based catalyst. The FTS product distribution of the feedstock is shown in Figure 3 and consists of a mixture of mainly a-olefins and n-paraffins that has been previously optimized to direct production towards heavy paraffins (Fernandes, 2005).

As expected, an increase in temperature increases the formation of lighter products narrowing the hydrocarbon product distribution. High temperatures (over $600 \mathrm{~K}$ ) produce very rapidly a great amount of hydrocarbons in the light gas and gasoline cuts, leaving very little amounts of heavy paraffins. Low temperatures $(550 \mathrm{~K})$ favor a mild hydrocracking and only hydrocarbons with long chains undergo cracking, yielding a product with higher percentage of diesel. At mild temperatures $(580 \mathrm{~K})$ the hydrocarbons in the diesel cut begins to undergo cracking, yielding more gasoline without further cracking to produce light gases (Figure 4).

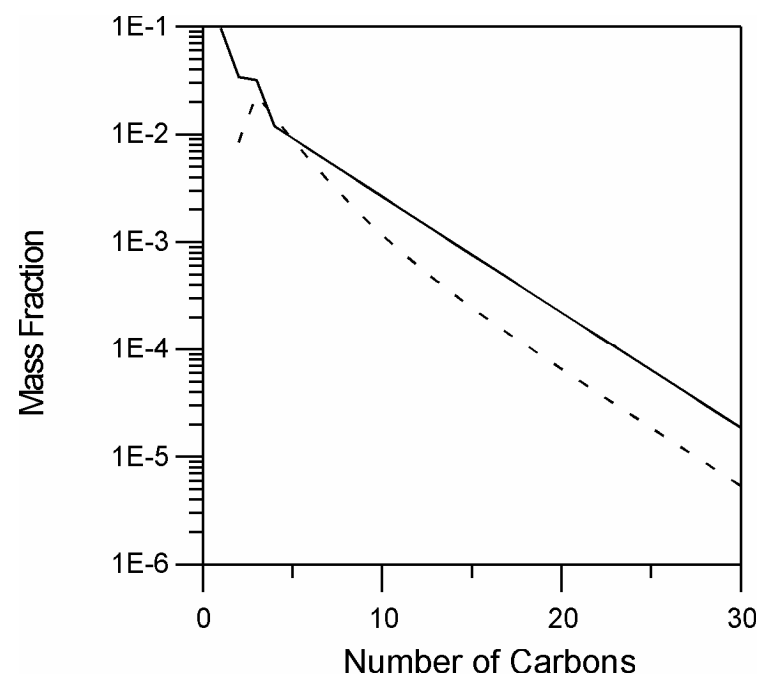

Figure 3. Carbon number distribution of the FTS product used as feedstock. Full line represents total hydrocarbons and dashed lines represent olefin and paraffin contents.

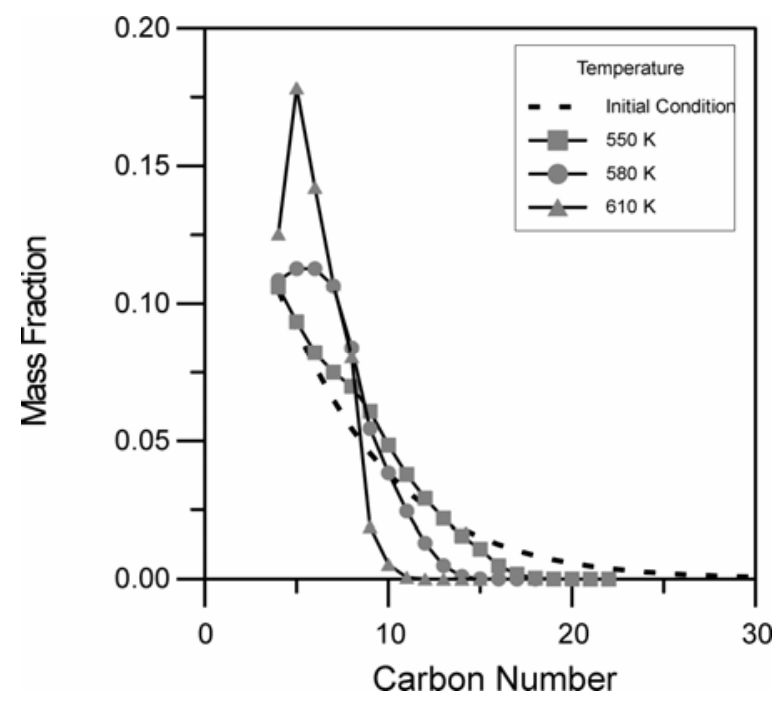

Figure 4. Product distribution as a function of the hydrocracking temperature (Processing time: 15 min). Dashed line represents the initial product distribution.

\section{Optimization}

Optimization of the hydrocracking process was conducted searching for the operating conditions (temperature and processing time) that result in the highest production of gasoline, diesel and heavy paraffins $\left(\mathrm{C}_{12}-\mathrm{C}_{20}\right)$. A program in Fortran was 
developed in order to maximize the production of these cuts, using the method of quasi-Newton and a finite-difference gradient. The optimization problem that was solved can be described as:

Find: $\mathrm{T}, \mathrm{t}$

Maximize: Product mass fraction (g product cut / g total hydrocarbon) $\max \left\{\Phi=\Sigma \mathrm{w}_{\mathrm{i}}\right\}$

where product is gasoline, diesel or waxes within the range of operating conditions: $550 \mathrm{~K}<\mathrm{T}<630 \mathrm{~K}$

Table 2 presents the best operating conditions obtained for the hydrocracking of the FTS product into gasoline, diesel and heavy paraffins cuts. Figures 5 to 7 shows the hydrocarbon product distribution for the optimized process.

Table 2. Best operating conditions obtained for the hydrocracking of the FTS product into gasoline, diesel and heavy paraffins cuts.

\begin{tabular}{|l|c|c|}
\hline Product & $\begin{array}{c}\text { Time } \\
{[\mathrm{min}]}\end{array}$ & $\begin{array}{c}\text { Temperature } \\
{[\mathrm{K}]}\end{array}$ \\
\hline Gasoline & 90.2 & 560 \\
Diesel & 0.5 & 560 \\
Wax & 0.1 & 560 \\
\hline
\end{tabular}

When gasoline is the desired product, the hydrocracking process is very successful and an increase of $50 \%$ is observed on the mass fraction of gasoline after $90.2 \mathrm{~min}$ at $560 \mathrm{~K}$ (Figure 5). This result is very promising because the theoretical maximum increase that could be obtained is of $89 \%$ (considering that all hydrocarbons heavier than the gasoline cut were cracked and no gasoline cut hydrocarbons undergo cracking).

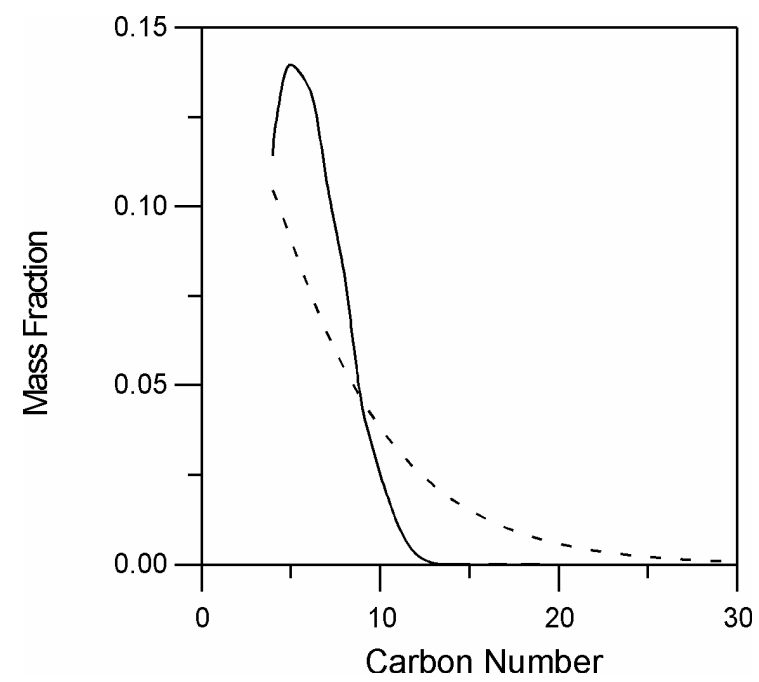

Figure 5. Product distribution after hydrocracking for the optimization of gasoline fraction. Full line represent the final product distribution. Dashed line represent the initial product distribution.
Both diesel and heavy paraffin cuts need the use of low temperatures in order to enhance the selectivity of the cracking reaction, since as shown in Figure 3, high temperatures favors only the production of gasoline cut.

An increase of $16 \%$ in the diesel cut was obtained after hydrocracking (Figure 6). This enhancement is also considerable, since the maximum theoretical enhancement would be of $26 \%$.

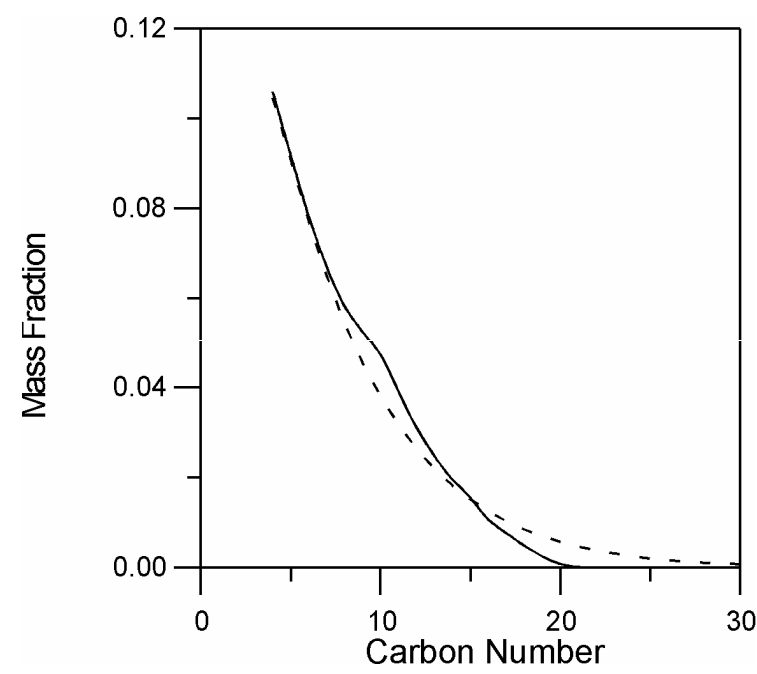

Figure 6. Product distribution after hydrocracking for the optimization of diesel fraction. Full line represent the final product distribution. Dashed line represent the initial product distribution.

On the other hand an increase in the heavy hydrocarbons cut $\left(\mathrm{C}_{15}-\mathrm{C}_{20}\right)$ was not possible and a decrease in this fraction was observed. The 6\% decrease in the heavy hydrocarbons cut after only 1 min of hydroprocessing demonstrates that the FTS product used in the simulations was already optimized to direct the production of hydrocarbons towards the wax cut $\left(\mathrm{C}_{15+}\right)$ (Figure 7).

\section{CONCLUSIONS}

The hydrocracking of a FTS product consisting of $\mathrm{C}_{4}$ to $\mathrm{C}_{30}$ paraffins and olefins has been studied by means of a mathematical model aiming process optimization.

The results have shown that the enhancement on the production of gasoline can be considered high, as well as the conversion into diesel. The amount of waxes in the final product is reduced to almost zero and the amount of light gases produced is also low, leading a very high selectivity into transportation fuels.

The process shows to be an important step in the production of diesel and gasoline through the Fischer-Tropsch synthesis, and further studies 


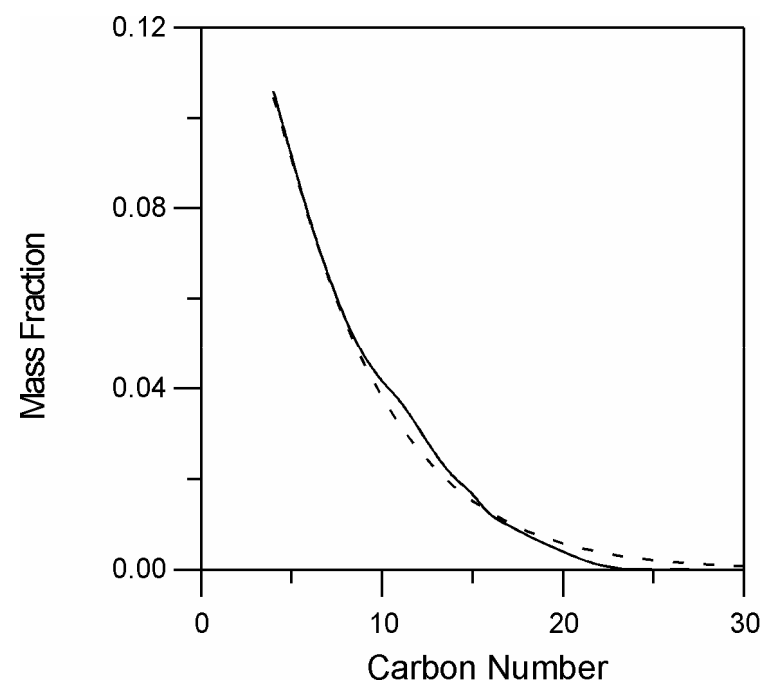

Figure 7. Product distribution after hydrocracking for the optimization of wax $\left(\mathrm{C}_{12}-\mathrm{C}_{20}\right)$ fraction. Full line represent the final product distribution. Dashed line represent the initial product distribution.

\section{ACKNOWLEDGEMENTS}

The authors gratefully acknowledge the financial support of the Brazilian research funding institution CNPq.

\section{REFERENCES}

Calemma, V., Peratello, S., and Perego, C., 2000. Hydroisomerization and hydrocracking of long chain n-alkanes on Pt/amorphous $\mathrm{SiO}_{2}-\mathrm{Al}_{2} \mathrm{O}_{3}$ catalyst. Applied Catalysis A, Vol. 190, pp. 207-218.

Fernandes, F.A.N., 2005. Polymerization kinetics of Fischer-Tropsch reaction on iron based catalysts and product grade optimization. Chemical Engineering Technology, Vol. 28, pp. 930-931.

Froment, G.F., 1987. Kinetics of the hydroisomerization and hydrocracking of paraffins on a platinum containing bifunctional Y-zeolite Catalysis Today, Vol. 1, pp. 455-473.

Li, X., Asami, K., Luo, M., Michiki, K., Tsubaki, N., and Fujimoto, K., 2003. Direct synthesis of middle iso-paraffins from synthesis gas. Catalysis Today, Vol. 84, pp. 59-65.

Schweitzer, J.M., Galtier, P., and Schweich, D., 1999. A single events kinetic model for the hydrocracking of paraffins in a three-phase reactor. Chemical Engineering Science, Vol. 54, pp. 24412452.

Sie, S.T., Senden, M.M.G., and van Wechem, H.M.H., 1991. Conversion of Natural Gas to Transportation Fuels via the Shell Middle Distillate Synthesis Process (SMDS). Catalysis Today, Vol. 8, pp. 371-381.

Pellegrini, L., Locatelli, S., Raselle, S., Bonomi, S., and Calemma, V., 2004. Modeling of FischerTropsch products hydrocracking. Chemical Engineering Science, Vol. 59, pp. 4781-4785.
Walendziewski, J.. Pniak, B., and Malinowska, B., 2003. Selectivity of platinum-zirconia catalysts in n-paraffins hydroisomerisation process. Chemical Engineering Journal, Vol. 95, pp. 113-121.

Zhou, Z., Zhang, Y., Tierney, J.W. \& Wender, I., 2003. Hybrid zirconia catalysts for conversion of Fisher-Tropsch waxy products to transportation fuels. Fuel Processing Technology, Vol. 83, pp. 67-80. 